\title{
Modifying the Balanced Scorecard for a Network Industry The Case of the Clearing Industry
}

\author{
Michael Chlistalla and Torsten Schaper \\ Goethe-University Frankfurt, Chair of e-Finance, Grüneburgplatz 1, \\ 60323 Frankfurt, Germany \\ \{Chlistalla, Schaper\}@wiwi.uni-frankfurt.de
}

\begin{abstract}
The Balanced Scorecard (BSC) is a well-established framework for the management of a company as it integrates financial and non-financial perspectives. Little attention has been given to its theoretical and conceptual valuation. We illustrate how the stakeholder value theory corresponds with the concept of the BSC and show the importance of underlying cause-and-effect relationships between its perspectives. For the case of clearing in Europe which is currently facing profound changes, we present our three-phased approach how to adjust and to extend Kaplan and Norton's original concept. We modify the generic BSC by adding risk management as a separate perspective and by integrating competition and IT. Based on multiple case studies, we then validate whether the modified BSC is suited to meet the specifics of the clearing industry.
\end{abstract}

Keywords: Performance Management, Balanced Scorecard, Network Industry.

\section{Introduction}

Companies use an average of 13 management tools or frameworks at the corporate level. Many of these are tools intended to help measure or monitor the performance of an organization. Within the most popular performance related frameworks $(57 \%)$ is the BSC [21]. Kaplan and Norton's BSC [13] represents a holistic instrument of corporate management as it integrates a variety of perspectives. The BSC can help the management implement and communicate a strategy within the organization. As the theoretical and conceptual valuation of the BSC in academic literature is rather sparse and any systematic methodology for deriving a tailored BSC is non-existent, the contribution of this paper is twofold: firstly, our aim is to illustrate how the stakeholder value theory corresponds with the concept of the BSC. Secondly, based on our findings and using the European clearing industry as an example, we demonstrate how to derive a BSC for a specific network industry. The European clearing industry is perfectly suited as a research object because it is currently facing enormous challenges and new forms of competition due to new regulatory requirements. We show that the modified BSC is a suitable tool for performance measurement in clearing houses. Our research is also valuable for practitioners as these modifications can serve as a basis for a re-design of current Management Information Systems in this industry. The 
paper is organized as follows. First, performance measurement with the BSC is introduced, followed by a literature review and a classification of the concept of the BSC into the theories of corporate governance. The next section introduces our approach for modifying a BSC which consists of three phases: initiation, derivation and implementation. The derivation phase is in focus of this paper; it describes the concept of central counterparty (CCP) clearing as well as recent trends in this industry, identifies the relevant stakeholders and analyzes visions of selected clearing houses. On this basis, a holistic BSC for the clearing industry is derived. Subsequently, the research model for the evaluation of this modified BSC and its inherent cause-and-effect relationships is presented. It is followed by the empirical validation via multiple case studies. At last, the main results of this research are summarized.

\section{Theoretical Foundations of the BSC}

Performance measurement is a way to track performance over time to assess whether goals are met. The management thus involves two key areas: planning and control. Every organization requires plans and a mechanism by which execution against the plan can be controlled [15]. A variety of performance measurement systems exist. The earliest system is the DuPont-System of Financial Control [4]. It is based on an accounting measure, the Return on Investment (ROI), which serves both as an indicator of the efficiency of the firm's operating departments and as the measure of financial performance of the company as a whole [11]. Another method frequently used by organizations to support strategic decisions and to identify process improvement capabilities is Activity-Based Costing (ABC), firstly defined by Kaplan and Cooper [12]. Both approaches are predominantly finance-focused: while ROI focuses on the fact that returns on assets can be expressed in terms of the profit margin and asset turnover, $\mathrm{ABC}$ is likewise lopsided as it only provides information on product and customer cost and profitability to the management. In order to obtain a holistic view on corporate performance, the ability of an institution to mobilize and exploit its intangible or invisible assets has become more decisive than investing and managing tangible assets only [13]. An approach that accommodates these needs is the BSC.

\subsection{The Balanced Scorecard}

The BSC translates the vision of an organization into a comprehensive set of measures and provides the framework for strategic measurement and management. The measures represent a balance between external measures for shareholders and customers, and internal measures of critical business processes, innovation, and learning. By providing explicit links between strategy, goals, performance measures, and outcomes, the BSC helps to achieve high-level performance. The BSC is a powerful tool for communicating strategic intent and motivating performance towards strategic goals [10]. The success of the implementation of a strategy is assessed by four perspectives (see Figure 1) which are described in detail by Kaplan and Norton [13][14]. 


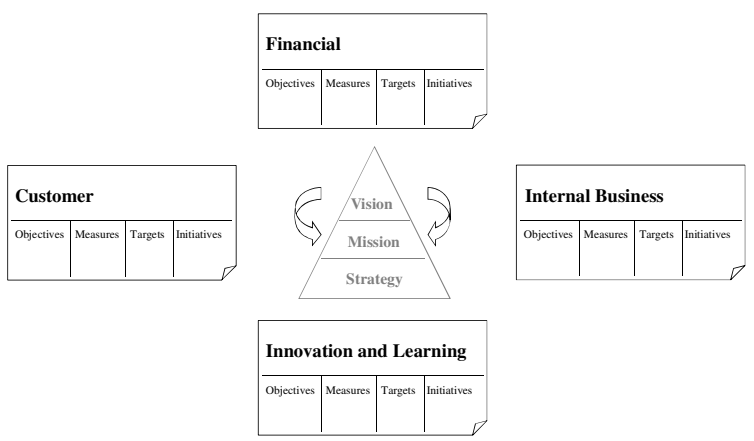

Fig. 1. Four perspectives of the Balanced Scorecard [14]

Cause-and-effect relationships are an essential part of second generation BSCs. These relationships between measures across perspectives were introduced in the mid 1990s, documenting objective-to-objective relationships. Alternatively called strategy maps or strategy linkage models, these relations differentiate performance measurement systems like the BSC from simple key performance indicator lists [14][16], which present an ad-hoc collection of measures to managers but do not allow for a comprehensive view on corporate performance. Instead, performance measurement systems like the BSC try to model the relations of the underlying value chain in cause-and-effect relationships (see Figure 2) to allow prediction of value chain performance measures, communication and realization of the corporate strategy [2].

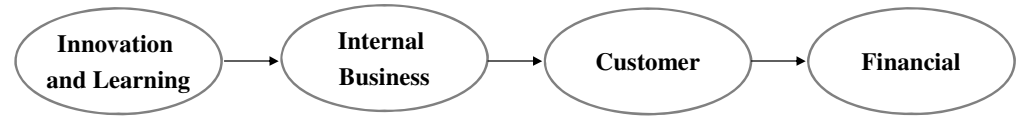

Fig. 2. Cause-and-effect relationships of the BSC [13][25]

\subsection{Literature Review}

Little attention has been given to the theoretical and conceptual valuation of the BSC, which has only been treated rudimentarily in academic literature [15]. The BSC can be positioned within several concepts of academic theories on corporate governance: The Systems Theory [15], the Shareholder Value Theory [20] and the Stakeholder Value Theory [19]. While the shareholder perspective regards disciplining managers in order to maximize shareholder value as the fundamental goal of the corporation [5], the stakeholder perspective extends this goal to include the stakeholders' welfare rather than concentrating on the shareholder alone [19]. The stakeholder perspective is actually an extension of the shareholder perspective, broadening the purpose of the corporation from maximizing shareholders' wealth to serving wider interests of stakeholders fairly and emphasizing corporate efficiency in a social context. A stakeholder is any group or individual who can affect or is affected by the achievement of the organization's objectives. Thus, two attributes can be defined to identify stakeholders: power to influence the firm and the legitimate claim or interest in the firm [9]. 
While Kaplan and Norton merely propagate their concept without in-depth discussion or critical assessment [1], Nørreklit [17] is among the first to examine the extent to which there is a cause-and-effect relationship among the four areas of measurement within the BSC. She discusses whether the BSC is able to link strategy to operational metrics that managers can understand and influence, concluding that there is no causal but rather a logical relationship among the areas of the BSC analyzed. Moreover, she suggests some changes to, and development of, the scorecard in order to ensure its organizational and environmental rooting. Blumenberg and Hinz [2], too, focus on the causalities within the BSC stating they are neither thoroughly introduced in theory nor applied in practice in a sound way. Their research is based on Fenton and Neil's [8] conclusions that "Bayesian belief nets (BBNs) were by far the best solution for [handling] genuine cause and effect relationships". In order to support organizations in introducing a $\mathrm{BSC}$, they present $\mathrm{BBNs}$ as an approach to model corporate causality relationships within the $\mathrm{BSC}$, acknowledging that - due to the nature of a $\mathrm{BBN}$ as a directed acyclic graph - a BSC may not exhibit loops within its underlying cause-andeffect relationships. Considering the usefulness of a sound stakeholder analysis for successful corporate governance, it is advisable and valuable to design the perspectives of a BSC in consideration of the relevant stakeholders. However, the lack of cause-and-effect relationships among the various groups of stakeholders as well as their limited - if not inexistent - effect and foundation on the corporate strategy do not allow for a purely stakeholder-oriented scorecard [15].

\section{Deriving a BSC for a Clearing House}

In order to derive a BSC for a specific industry and to implement it afterwards for a particular company in that industry, we propose a three-phased approach. The process preferably starts with an initiation phase, which includes the familiarization with the literature on performance measurement in general and on the concept of the BSC in specific. The outcome (milestone) of this phase is a comprehensive understanding of the generic BSC. The second phase is the derivation of the industry-specific BSC, which is in focus of this paper. This phase is subdivided into three steps and can further be structured into a number of consecutive activities:

- Step 1 (Analysis): Obtain a thorough understanding of the business itself and the challenges that are currently affecting the industry; Identification of relevant stakeholders and development of an understanding of their interests; Analysis of corporate websites, annual reports, organizational charts, and corporate visions, missions and strategies of the specified industry.

- Step 2 (Design): Deriving the modified perspectives for the specified industry; Model the underlying cause-and-effect relationships.

- Step 3 (Validation).

Concomitantly, we discussed these steps with selected industry experts and academics. In various feedback loops, their comments inspired our approach. The third phase, which leads to a company-specific BSC, will arguably be structured similarly to phase 2. As the implementation of a company-specific BSC, however, requires delving intensely into figures and measures that are proprietary for a single company, this 


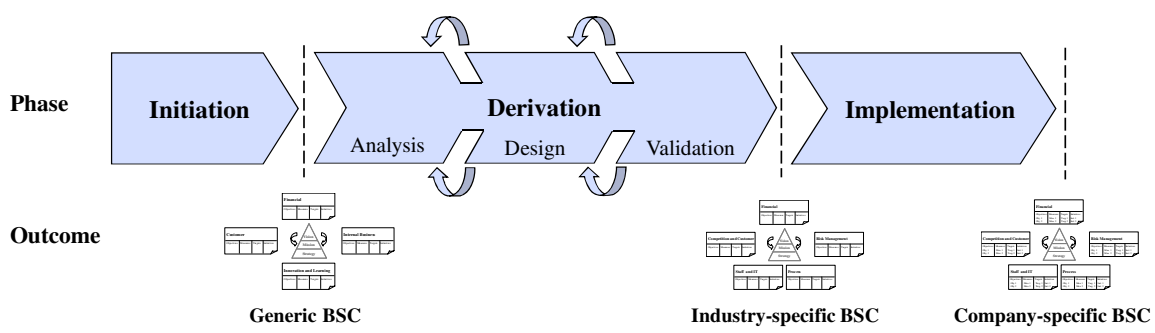

Fig. 3. Approach for deriving a BSC

phase will not be further discussed within this paper. Figure 3 illustrates graphically our approach for deriving a modified BSC. The focus of the outcomes narrows as we move stepwise from left (general BSC) to right (company specific BSC).

\subsection{Central Counterparty Clearing}

Clearing and settlement cover all processes after a trade has been executed to finalize the transaction. The purpose of clearing is the efficient handling of risks inherent to concluded, but unfulfilled contracts. Clearing confirms the legal obligation from the trade. It involves the calculation of the mutual obligations of market participants and determines what each counterpart receives. Central counterparty (clearing) is not included in the definition of clearing. A central counterparty (CCP) is an entity that interposes itself between the transactions of the counterparties in order to assume their rights and obligations, acting as a buyer to every seller and as a seller to every buyer. The original legal relationship is thus replaced by two new legal relationships. The CCP absorbs the counterparty risk and guarantees clearing and settlement of the trade [26]. A CCP is a service offered by a clearing house. An important driver for the increased use of CCP services in cash markets is the increased use of electronic order books to match trades. The anonymity of the electronic order books complicates the risk management of market participants, as counterparty risk cannot be managed through their choice of counterparty. A CCP is a useful service to clear and settle anonymous trades, since the market participant can manage its counterparty risk towards the CCP. It is important to notice that a CCP takes principal risks and therefore separates itself from the classical post-trade providers, which usually only act as agents. It is essential that the $\mathrm{CCP}$ has a functioning risk management system. Besides performing the CCP clearing function, most clearing houses provide further services like collateral management and netting. They enhance the efficiency of clearing and settlement and redistribute the risk between market participants [26].

\subsection{The European Clearing Industry}

The clearing industry is characterized by network effects and economies of scale and scope [18]. In Europe, the clearing industry used to operate its business facing no competition. Recently, clearing houses are exposed to an increasingly competitive environment. Over time, different governance structures have established: for-profit, not-for-profit, user-owned, and government-owned with hybrid forms existing. 
Between 1999 and 2004, a consolidation of clearing houses in Europe took place: the number of equities and derivatives clearing houses declined from 14 to eight due to various mergers and alliances [23]. Since then, a small number of equity CCPs have been newly formed. Today, nine equity clearing houses serve the European markets.

Since 2006, the European Code of Conduct for Clearing and Settlement intends to establish a strong European capital market and to allow investors the choice to trade any security within a consistent, coherent, and efficient European framework. The aim of the Code is to offer market participants to choose between their preferred provider of services separately at each layer of the securities trading value chain (trading, clearing and settlement). The Code is a voluntary self-commitment and adheres to a number of principles on the provision of post-trading services for cash equities. The implementation consists of three phases and was finalized by the end of 2007. The guidelines for access and interoperability provide the basis for the development of links between service providers: more than 80 requests for access and interoperability were addressed until today, the majority of which affect clearing houses.

\subsection{Stakeholders of a Clearing House}

The main stakeholders of a clearing house are identified and described in the following:

- Shareholders have the power to influence the clearing house as they provide the company with capital and have a legitimate interest in the clearing house based on their ownership. As owners of the clearing house, they expect the maximization of their return on investment.

- Suppliers provide the clearing house with necessary infrastructure and services and earn revenues from the clearing house.

- Users can be classified into direct and indirect users. Direct users contribute to the risk capital of the clearing house and pay fees for the services. Thus, they have economic influence over the clearing house and a legitimate claim on the clearing house to apply sound risk management and to provide secure and efficient clearing services at a low price.

- Employees provide the clearing house with human resources and expect to receive adequate compensation and desirable working conditions.

- Community and public authorities provide the regulatory and supervisory framework in which a clearing house conducts its business. They have an interest in the risk management, free and fair competition, and cost-efficiency of the clearing house. Examples are the national banks or the European Central Bank, public authorities at national level and at EU level, and other institutions.

- Regulated Markets and Multilateral Trading Facilities (MTFs) have the capacity to operate a CCP on their own or to appoint one to offer clearing services for the securities traded on their platform. Regulated markets and MTFs have a legitimate interest in the fees as lower clearing fees contribute to the attractiveness of the trading platform because of lower total transaction costs. Netting services and risk management are also important for the safety and efficiency of the regulated market or MTF. 


\subsection{Company Visions of Clearing Houses}

The BSC translates an organization's vision into a comprehensive set of measures and provides the basis for strategic management. A vision is a short, concise, and inspiring statement from the top management of what the organization intends to achieve, often stated in competitive terms. We studied corporate visions of clearing houses, two of which differing in terms of their governance structure are detailed in the following:

- EMCF (for profit): In an increasingly complex, yet ever more convergent world, innovation, speed and agility will be as crucial as scale, track record and reach. We will stand out as a professional international financial services brand, recognized for our ability to deliver superior and sustainable stakeholder value by constantly anticipating and surpassing the needs of customers, investors, employees, partners and communities wherever we do business.

- KELER (government-owned): KELER shall be an acknowledged clearing house and depository with a leading position in the Central Eastern Europe region that operates in an innovative way, in the form of a specialized credit institution. It shall be a dominant, active participant of the clearing house systems infrastructure of the region. KELER shall be successful, because its customers are satisfied with its services, shall manage to increase its shareholder's value, and appreciate and retain its ambitious team of employees.

A detailed analysis shows that both clearing houses apparently apply the stakeholder value theory. Elements of the stakeholder theory such as shareholders, customers, and employees are incorporated in both corporate visions emphasizing their importance for the top management. Moreover, further strategic perspectives from Kaplan and Norton's BSC are reflected:

- "needs of investors" / "increase its shareholder's value" $\rightarrow$ represents the financial perspective;

- "needs of customers" / "customers are satisfied" $\rightarrow$ represents the customer perspective;

- "needs of employees" / "retain its ambitious team of employees" $\rightarrow$ represents the innovation and learning perspective;

- "innovation, speed and agility" / "operates in an innovative way" $\rightarrow$ partially represents the internal business and the innovation and learning perspectives.

However, certain aspects of the corporate visions cannot be mapped to the stakeholder value theory or the traditional perspectives of the BSC:

- "more convergent world" / "leading position in the Central Eastern Europe region" $\rightarrow$ We interpret this as an indicator for the company's reaction towards the changing competitive European environment.

- "innovation, speed and agility" / "operates in an innovative way" $\rightarrow$ We interpret this as extension of the internal business and the innovation and learning perspectives by the aspect of IT.

To fit the clearing industry, these extending elements of the corporate visions require a modification of the original BSC. 


\subsection{The Modified BSC for a Clearing House}

Discussions with industry experts and academics revealed that most clearing houses are currently overhauling and institutionalizing their internal performance measurement and management systems. Until recently, these were often rather straightforward tools based on e.g. simple Excel spreadsheets. The recent trends and developments in the European clearing industry and the intensified complexity resulting from increasing volumes and the potential for system risk as well as from competition and the inter-CCP risk management involved were named as reasons. As a result of our analyses, we extend the "Customer" perspective to "Competition and Customer" as Tate [24] argues that competitors should be included in a company's BSC. Additionally, we suggest emphasizing the importance of IT in order to take into account the progressive automation of post-trade processes [6]. Although not included in the corporate visions, we introduce "Risk Management" as a new perspective as it is explicitly considered in the organizational structure of most clearing houses. This extension follows e.g. Ahn [1] who demands that each fundamental goal should be represented by a perspective or Rosemann and Wiese [22] who add a new fifth project perspective to increase completeness and quality of the management report. Extensive discussions with academics and industry representatives indicate support of these modifications. We propose the following modified BSC perspectives for the clearing industry:

Financial Perspective. The financial perspective does not differ from Kaplan and Norton's BSC [14]. This component of the BSC looks at the projects from a financial perspective and discusses financial considerations. We propose to align the financial objectives to the shareholder value theory by introducing value-based measures. In case the clearing house operates on a not-for-profit basis, we recommend focusing on cost-related figures and alignment to the stakeholder value theory.

Competition and Customer Perspective. As stated by Kaplan and Norton [14], customer focus and customer satisfaction are of paramount importance to the success of a company. Due to the newly arising competition, we propose to extend the "Customer" perspective to "Competition and Customer" in order to integrate the monitoring of the strategic actions triggered by the competitive dynamics into the company's BSC. These may include strategies of expansion into new markets or the defense of the established markets.

Process Perspective. We propose to rename the "Internal Business" perspective as introduced by Kaplan and Norton [13] as "Process" perspective. As the original "Internal Business" perspective includes support processes, we suggest focusing on the mission-oriented core processes. Those supporting processes that are essential for a clearing house (such as risk management and IT) are addressed in individual perspectives. The focus of this perspective emphasizes what the clearing house has to do well to meet the customer needs. An appropriate measure could be the rate of straight-through processing.

Risk Management Perspective. A clearing house absorbs the counterparty risk and guarantees clearing and settlement of a trade [26]. The current global financial crisis has shown that markets with an established clearing house were able to handle the systemic risk appropriately. As risk management is the core operation of a clearing 
house, we propose to consider this core function in an individual perspective. Banks' BSCs often feature such a perspective in order to increase the awareness for operational risks and to facilitate the process of risk management [27]. As measures for this perspective we propose, for instance, the time between margin cycles, the accuracy of margining, the institution's financial rating or the frequency of default funds usage.

Staff and IT Perspective. As stated by Kaplan and Norton [14], "Innovation and Learning" are essential in order to support the critical operations of a clearing house. While the original perspective focuses on staff mainly, we recommend extending this perspective by IT and renaming it to "Staff and IT". The most prominent driver of technological efficiency was the almost complete automation of the post-trade processes by the implementation of innovative IT systems. Continental European markets adopted paperless processes earlier than other markets and are currently marking significant IT investments [6]. As measures for this perspective we propose, for instance, system availability and timeliness of strategic IT projects.

The basic cause-and-effect relationships of the perspectives from Kaplan and Norton [14] remain constant. Adding the risk management perspective, though, requires an adaptation of these relationships. As a clearing house absorbs the counterparty risk of all client trades processed by taking the principal risk (which the client would otherwise need to bear by himself), we are of the opinion that risk management mainly affects the Competition and Customer perspective. Figure 4 represents this in a possible cause-and-effect relationship chain.

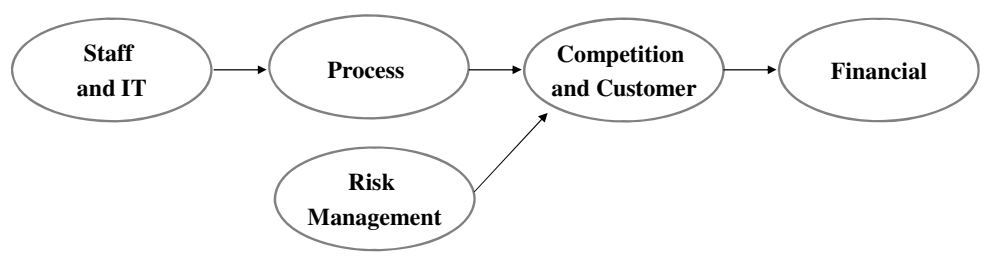

Fig. 4. Possible cause-and-effect relationships of the BSC for a clearing house

\section{Validating the BSC}

In order to show that the BSC is a suitable steering and monitoring tool for clearing houses in the changing European environment, we test the suitability of the original BSC by means of a case study. In this context, we also validate the traditional perspectives from Kaplan and Norton [14] regarding their applicability for a clearing house. In a second step, we reiterate this process for the modified BSC. In a last step we compare the results for both scorecards. Figure 5 lists our hypotheses, and the stated literature shows their origin. The hypotheses are tested in the following section.

In order to test the hypotheses, an adequate and accepted method would be to conduct a survey among the focus group of market participants. However, the case of clearing houses is very distinctive as their quantity - and hence the viable population for a survey - is very limited. The number of equity clearing houses in Europe 


\begin{tabular}{|l|l|}
\hline \multicolumn{1}{|c}{ Hypotheses } \\
\hline \multicolumn{1}{|c|}{ H1: The Balanced Scorecard is a suitable tool for performance measurement of a clearing house in the } \\
changing environment.
\end{tabular}

Fig. 5. Hypotheses

currently amounts to nine only. We therefore instead decided in favour of the case study as a research strategy, factoring in that such research relies on theoretical, not statistical sampling [7]. The case study method is preferred when asking "how" and "why" questions, or "what" questions with an explanatory character [28]. It is not limited to obtain a static snapshot, but allows to understand developments, process sequences, and cause-and-effect chains as well as to draw data-based conclusions that are practically relevant. Furthermore, as defined by Yin [23], case study research is appropriate when the investigator has little or no control over the events, meaning that relevant behaviors cannot be manipulated. In addition, case study research is appropriate when the focus is on a contemporary phenomenon with real-life context. To achieve the necessary rigor, it is essential to explicitly and properly define the research question and the unit of analysis in the design and preparatory phase. Like field studies, case studies typically utilize questionnaires, coded interviews, or systematic observation as techniques for data gathering [23]. The methods for collecting the data for a case study are not limited to specific methods and are often combined. It is worth mentioning that the expert interview as an applied research methodology differs from qualitative interviews and also allows questioning experts according to their experience and interpretation of relevant research topics [3].

\subsection{Case Study}

Due to the sensitivity of the requested information in an industry as competitive as clearing in Europe, it is obvious that potential participants are hardly willing to disclose their expert views with their affiliation mentioned. We therefore decided to assure absolute anonymity. We guarantee construct validity during the analysis phase by using multiple sources of evidence (such as academic literature, corporate websites and balance sheets). Our case study consists of interviews with six industry experts from 
three different clearing houses who each have more than 20 years of experience in the financial industry. With three out of nine clearing houses currently operating throughout Europe, this represents coverage of one third of the market. The open-ended, pre-structured interviews were guided and accompanied, and were conducted by two researchers, with interviewees selected according to their hierarchy and expertise. It must be noted that due to the high level of automation, clearing is not a peopleintensive business; accordingly, the number of experts in strategic management positions is limited. Propositions used in the cases are grounded theoretically and explicitly stated [28]. Some interview partners provided additional documentation (such as organizational charts, structure of current PMS, mission statements). The cases were evaluated on the basis of final, written, and mutually agreed interview transcripts.

Case A. The interviewees of Case A are from the senior management of one of the ten largest equity clearing houses worldwide. Formulating hypothesis H1, we intended to find out whether the BSC in its basic form is a suitable tool for performance measurement of a clearing house. Towards this statement, the interviewees were neutral ${ }^{1}$. The intention of the hypotheses $\mathrm{H} 2 \mathrm{a}$ to $\mathrm{H} 5 \mathrm{a}$ ( $\mathrm{H} 2 \mathrm{~b}$ to $\mathrm{H} 6$ respectively) was to find out whether the four perspectives of Kaplan and Norton's original BSC and the five perspectives of our modified BSC respectively are necessary and important for measuring the performance of a clearing house. The following table reflects how, according to the interviewees, the perspectives should ideally be considered for the performance measurement system of a clearing house. The first and fourth columns of the table list the perspectives; the second (fifth) column shows the percentage of each perspective's ideal consideration for performance measurement in clearing houses as attributed by the interviewees. In order to make the figures comparable, we relate in column 3 (column 6) this percentage to the percentage that would be attributed to each perspective assuming equal distribution, that is 25 percent for each original perspective and 20 percent for each modified perspective.

Table 1. View of Case A on ideal consideration of Kaplan and Norton's perspectives versus ideal consideration of the modified perspectives

\begin{tabular}{|c|c|c|c|c|c|}
\hline & $\begin{array}{l}\text { Ideally } \\
\text { considered }\end{array}$ & $\begin{array}{l}\text { Consideration in } \\
\text { relation to equal } \\
\text { distribution }\end{array}$ & & $\begin{array}{l}\text { Ideally } \\
\text { considered }\end{array}$ & $\begin{array}{l}\text { Consideration in } \\
\text { relation to equal } \\
\text { distribution }\end{array}$ \\
\hline Financial & $30 \%$ & 1.2 & Financial & $15 \%$ & 0.75 \\
\hline Customer & $30 \%$ & 1.2 & $\begin{array}{l}\text { Competition } \\
\text { and Customer }\end{array}$ & $30 \%$ & 1.50 \\
\hline $\begin{array}{l}\text { Internal } \\
\text { Business }\end{array}$ & $20 \%$ & 0.8 & Process & $10 \%$ & 0.50 \\
\hline \multirow[t]{2}{*}{$\begin{array}{l}\text { Innovation } \\
\text { and Learning }\end{array}$} & $20 \%$ & 0.8 & $\begin{array}{l}\text { Staff } \\
\text { and IT }\end{array}$ & $10 \%$ & 0.50 \\
\hline & & & $\begin{array}{l}\text { Risk } \\
\text { Management }\end{array}$ & $35 \%$ & 1.75 \\
\hline
\end{tabular}

1 Ticking "4" on a 7-item Likert scale (where 1 is "totally disagree", 2 is "strongly disagree", 3 is "disagree", 4 is "neutral", 5 is "agree", 6 is "strongly agree", and 7 is "totally agree"). 
Columns 1 through 3 of Table 1 display the importance the industry experts attribute to Kaplan and Norton's perspectives for the performance measurement system of a clearing house, illustrating that the financial and the customer perspective are given slightly more weight than the internal business and innovation and learning perspectives. Columns 4 through 6 present the experts' attitude towards our proposed modified perspectives. A clear ranking can be observed, starting with risk management as the most important perspective, followed by competition and customer as second. The remaining perspectives are ranked below average. A clear shift of focus can be observed: Interestingly, the newly introduced risk management perspective is regarded as the most important (35\%). At the same time, the financial and the staff and IT perspectives are ranked less significant. Finally, hypothesis $\mathrm{H} 7$ aims at documenting whether the modified BSC is better suited than the generic BSC as a performance measurement system for the clearing industry. Here, the interviewees strongly agreed ${ }^{2}$. Compared to the level of acceptance of hypothesis H1, this can be interpreted as evidence for accepting $\mathrm{H} 7$ and thus as a support of our modified BSC.

Case B. The interviewees of the second case are from the senior management of an equity clearing house which is not among the ten largest worldwide. The experts agreed $^{3}$ to hypothesis H1. The following table 2 reflects how, according to the interviewees, Kaplan and Norton's perspectives should ideally be considered. It illustrates that the customer perspective is most important since the experts allocate as much weight to it $(50 \%)$ as to all three remaining perspectives. Innovation and learning is also considered important $(30 \%)$ while interestingly the financial and the internal business perspectives are ranked far below average.

Table 2 also presents the experts' attitude towards our proposed modified perspectives. A clear ranking can be observed, starting with risk management and competition and customer as the most important perspectives, followed by staff and IT as

Table 2. View of Case B on ideal consideration of Kaplan and Norton's perspectives versus ideal consideration of the modified perspectives

\begin{tabular}{lcc|lcc}
\hline & $\begin{array}{c}\text { Ideally } \\
\text { considered }\end{array}$ & $\begin{array}{c}\text { Consideration in } \\
\text { relation to equal } \\
\text { distribution }\end{array}$ & & $\begin{array}{l}\text { Ideally } \\
\text { considered }\end{array}$ & $\begin{array}{c}\text { Consideration in } \\
\text { relation to equal } \\
\text { distribution }\end{array}$ \\
\hline Financial & $10 \%$ & 0.4 & Financial & $10 \%$ & 0.5 \\
Customer & $50 \%$ & 2.0 & $\begin{array}{l}\text { Competition } \\
\text { and Customer }\end{array}$ & $30 \%$ & 1.5 \\
$\begin{array}{l}\text { Internal } \\
\text { Business }\end{array}$ & $10 \%$ & 0.4 & Process & $10 \%$ & 0.5 \\
$\begin{array}{l}\text { Innovation and } \\
\text { Learning }\end{array}$ & $30 \%$ & 1.2 & Staff and IT & $20 \%$ & 1.0 \\
& & & Risk & $30 \%$ & 1.5 \\
\hline
\end{tabular}

\footnotetext{
2 Ticking "6".

3 Ticking "5".
} 
second most important perspective. The remaining perspectives are ranked below average. A clear shift of focus can be observed: Our newly introduced risk management perspective is regarded most important $(30 \%)$ while the two perspectives ranked most important previously lose weight. The experts strongly agreed ${ }^{4}$ to $\mathrm{H} 7$ that the modified scorecard is a suitable tool for performance measurement of a clearing house. Especially compared to the level of acceptance of $\mathrm{H} 1$, this can be interpreted as evidence for accepting $\mathrm{H} 7$ and thus as a support of our modified BSC.

Case C. The interviewees of the third case are from the middle and senior management of one of the ten largest equity clearing houses worldwide. The experts agreed ${ }^{5}$ to hypothesis H1. The following table again reflects how, according to the interviewees, the perspectives should ideally be considered ( $\mathrm{H} 2$ to H6). Table 3 shows the importance the industry experts attribute to Kaplan and Norton's perspectives and to our proposed modified perspectives, respectively, for the performance measurement system of a clearing house. In both instances, the statement was made that all perspectives are deliberately ranked uniformly and none is prioritized as the interviewees regarded all perspectives as highly connected and interrelated.

Table 3. View of Case C on ideal consideration of Kaplan and Norton's perspectives versus ideal consideration of the modified perspectives

\begin{tabular}{lcc|lcc}
\hline & $\begin{array}{c}\text { Ideally } \\
\text { considered }\end{array}$ & $\begin{array}{c}\text { Consideration in } \\
\text { relation to equal } \\
\text { distribution }\end{array}$ & & $\begin{array}{c}\text { Ideally } \\
\text { considered }\end{array}$ & $\begin{array}{c}\text { Consideration in } \\
\text { relation to equal } \\
\text { distribution }\end{array}$ \\
\hline Financial & $25 \%$ & 1.0 & Financial & $20 \%$ & 1.0 \\
Customer & $25 \%$ & 1.0 & $\begin{array}{l}\text { Competition } \\
\text { and Customer }\end{array}$ & $20 \%$ & 1.0 \\
$\begin{array}{l}\text { Internal } \\
\text { Business }\end{array}$ & $25 \%$ & 1.0 & Process & $20 \%$ & 1.0 \\
$\begin{array}{l}\text { Innovation an } \\
\text { Learning }\end{array}$ & $25 \%$ & 1.0 & Staff and IT & $20 \%$ & 1.0 \\
& & & Risk & $20 \%$ & 1.0 \\
\hline
\end{tabular}

The experts strongly agreed ${ }^{6}$ to $\mathrm{H} 7$ that the modified scorecard is a suitable tool for performance measurement of a clearing house. Compared to the level of acceptance of hypothesis $\mathrm{H} 1$, this can again be interpreted as evidence for accepting hypothesis $\mathrm{H} 7$ and thus as a support of our modified BSC.

Analysis of the Cases. All three cases do not discard hypothesis H1 that the BSC in its basic form is a suitable tool for performance measurement of a clearing house. In all three cases, the experts strongly agreed to $\mathrm{H} 7$ which states that the modified scorecard is a suitable tool for performance measurement of a clearing house. Comparing

\footnotetext{
4 Ticking "6".

5 Ticking " 5 ".

${ }^{6}$ Ticking " 6 ".
} 
the levels of acceptance of hypotheses $\mathrm{H} 1$ and $\mathrm{H} 7$ indicates support for our modified BSC; we therefore conclude that the modified BSC is better suited to fit the needs of a clearing house than the original BSC. The newly introduced risk management perspective finds strong support by the experts from Case A and B. Although Case C does not differentiate the perspectives by weight, the same relative weight is attributed to risk management as to all other perspectives. Also, the extended competition and customer perspective is top-ranked by the experts form Case A and B and equally ranked by the expert from Case $\mathrm{C}$. It is interesting that on inquiry two thirds of the experts interviewed stated to see potential for a new perspective that includes strategic and regulatory issues.

These results show that the concept of the BSC can be adapted to accommodate a specific industry. In order to make it applicable for a particular institution, the industry-specific BSC must be further adapted to the needs of a specific company.

\subsection{Cause-and-Effect Relationships within the Modified BSC}

Kaplan and Norton [14] point out that good BSCs are more than ad hoc collections of financial and non-financial measures and that the crucial point of the BSC is the linking together of the four areas of measurement in a causal chain that passes through all four perspectives. To accommodate this claim and owing to the fact that during the interviews we were able to observe that all experts are aware of interdependencies between the various perspectives, we further investigated the extent and direction of the cause-and-effect relationships during our case study. We asked the interviewees to state whether in their opinion interdependencies between any of the perspectives existed, and if so, to assess ${ }^{7}$ the degree of correlation. This approach was done separately for both the original and the proposed modified BSC perspectives. The interviewees are aware that there are correlations between most perspectives. The following figures, however, only include the stronger correlations. In contrast to figure 2, figure 6 shows an additional linkage between the perspectives "Innovation and Learning" and "Customer". Moreover, the interviewees are aware of a feedback relation between the financial and the customer perspective.

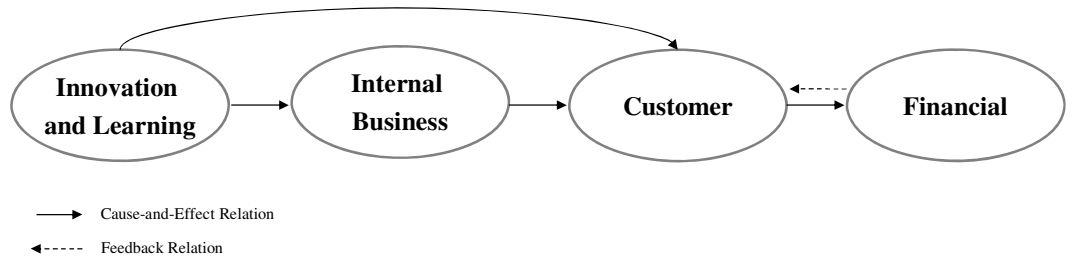

Fig. 6. Cause-and-effect and feedback relations in Kaplan and Norton's perspectives

\footnotetext{
${ }^{7}$ Using a 7-item Likert scale where 1 is "no correlation", 2 is "very weak correlation", 3 is "weak correlation", 4 is "rather weak correlation", 5 is "rather strong correlation", 6 is "strong correlation", and 7 is "very strong correlation".
} 
Concerning the perspectives of the modified BSC, the experts see similar causeand-effect relations as within the traditional BSC. The main difference can be seen in the cause-and-effects relations of the newly introduced "Risk Management" perspective (see figure 7). Moreover, the experts see feedback relations from the "Financial" perspective to the "Competition and Customer" and "Staff and IT" perspectives.

In case it is intended to model the cause-and-effect relations of the BSC by means of Bayesian Belief Networks (BBN) as proposed by Blumenberg and Hinz [2], the existence of feedback loops must be omitted as the concept of BBNs stipulates that the graph be acyclic. However, the experts emphasize the importance of these feedback loops from the "Financial Perspective" and the usage of the funds for the success of the strategy of the corporation. Therefore, it is essential to model the cause-andeffect relations including the feedback loops.

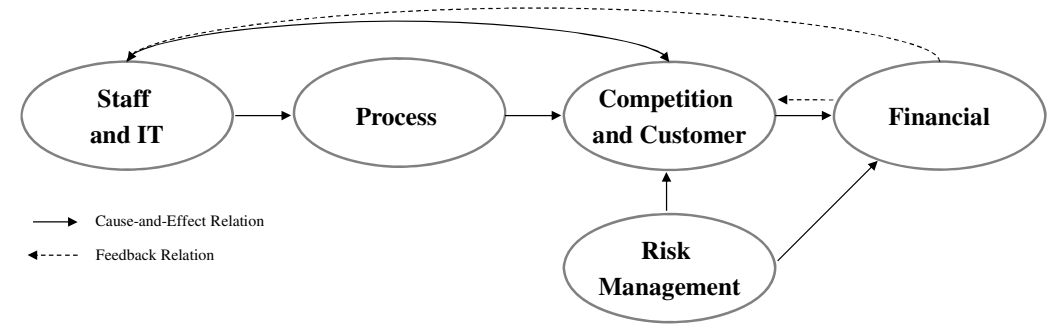

Fig. 7. Cause-and-effect and feedback relations in the modified perspectives

\section{Conclusion and Further Research}

The BSC is a well-established steering and controlling tool, allowing the management to set up objectives and to communicate these objectives and their performance towards the employees. We introduce the BSC as a funded approach for the management of a company and illustrate how the stakeholder value theory corresponds with the concept of the BSC. Based on our findings and using the European clearing industry as an example, we present a three-phased approach how to adjust and to extend Kaplan and Norton's original concept. Particularly risk management as the core function and key competence of a clearing house requires explicit and detailed consideration. We therefore add risk management as a separate perspective. Moreover, against the background of increasing competition and accounting for the industry's level of automation, we integrate competition and IT into the modified BSC.

In order to show that the BSC is a suitable tool for performance measurement of a clearing house in the changing European environment, we tested the suitability of the original and the modified BSC by means of a case study. The cases lead to two interesting results: firstly, they support the hypothesis that the BSC in general is a suitable tool for performance measurement in the clearing industry; secondly, they indicate that our modified BSC is better suited than the traditional BSC. Especially the introduction of a separate risk management perspective and the extension of the customer perspective by the aspect of competition are supported by the cases. Moreover, we show the existence of underlying cause-and-effect and feedback relations which need 
to be considered properly upon designing a BSC and choosing the appropriate perspectives. These findings can serve as a basis for the re-design of current Management Information Systems in the clearing industry.

In our further research we plan to analyze the potential of OTC clearing as a growth strategy for single clearing houses and the related chances and risks from their perspective, their users and regulators. Moreover, we plan to analyze the effects of competition and inter-CCP risk management considering systemic risk.

Acknowledgments. The authors gratefully acknowledge the support of the E-Finance Lab, Frankfurt for this work.

\section{References}

1. Ahn, H.: How to Individualise Your Balanced Scorecard. Measuring Business Excellence, 5-12 (2005)

2. Blumenberg, S., Hinz, D.: Enhancing the Prognostic Power of IT Balanced Scorecards. In: 39th Hawaii International Conference on System Sciences, Hawaii (2006)

3. Borchardt, A., Göthlich, S.E.: Erkenntnisgewinnung durch Fallstudien, Methodik der empirischen Forschung. In: Alberts, et al. (eds.) Gabler, Wiesbaden, pp. 33-48 (2007)

4. Brealy, R.A., Myers, S.C.: Principles of corporate finance. McGraw-Hill, New York (2000)

5. Copeland, T., Koller, T., Murrin, J.: Valuation: Measuring and Managing the Value of Companies, 2nd edn. Wiley, New York (1994)

6. Börse, D.: The European Post-Trade Market - An Introduction, White Paper (2005)

7. Eisenhardt, K.M.: Building Theories from Case Study Research. The Academy of Management Review 14(4), 557-573 (1989)

8. Fenton, N., Neil, M.: Software Metrics and Risk. In: 2nd European Software Measurement Conference (1999)

9. Freeman, R.E.: Strategic Management: A Stakeholder Approach. Pitman (1984)

10. Ittner, C.D., Larcker, D.E.: Innovations in performance measurement: Trends and research implications. Journal of Management Accounting Research (10), 205-238 (1998)

11. Kaplan, R.: The Evolution of Management Accounting. The Accounting Review 59(3), 390-418 (1984)

12. Kaplan, R., Cooper, R.: How Cost Accounting Systematically Distorts Product Costs. In: Kaplan, R., Bruns, W. (eds.) Accounting and Management: A Field Study Perspective. Harvard Business School Press (1987)

13. Kaplan, R., Norton, D.: The Balanced Scorecard: Measures that drive performance. Harvard Business Review, 77-80 (1992)

14. Kaplan, R., Norton, D.: Balanced Scorecard: Translating Strategy into Action. Harvard School Press (1996)

15. Körnert, J., Wolf, C.: Theoretisch-konzeptionelle Grundlagen zur Balanced Scorecard. University of Greifswald Discussion Paper No. 2 (2006)

16. Lawrie, G., Kalff, D., Andersen, H.: Balanced Scorecard and Result-Based Management: Convergent Performance Management Systems. In: Proceedings of the 3rd Annual Conference on Performance Measurement and Management Control, EIASM, Nice, France (September 2005)

17. Nørreklit, H.: The balance on the balanced scorecard - a critical analysis of some of its assumptions. Management Accounting Research 11(1), 65-88 (2000) 
18. Pirrong, C.: The Industrial Organization of Execution, Clearing, and Settlement in Financial Markets. In: CFS, DBAG and EFL Research Conference, Frankfurt (2008)

19. Prabhaker, R.: Governance and Stakeholding: How Different are the Shareholder and Stakeholder Models. New Economy 5(2), 119-122 (1998)

20. Rappaport, A.: Creating Shareholder Value. The new standard for business performance. B\&T, New York (1986)

21. Rigby, D., Bilbodeau, B.: Management Tools and Trends. Bain and Company (2005)

22. Rosemann, M., Wiese, J.: Measuring the Performance of ERP Software - a Balanced Scorecard Approach. In: Hope, B., Yoong, P. (eds.) Proceedings of the 10th Australasian Conference on Information Systems (ACIS 1999), Wellington, (with J. Wiese), December 1-3, pp. 773-784 (1999)

23. Schmiedel, H., Schönenberger, A.: Integration of Securities Market Infrastructures in the Euro Area. European Central Bank Occasional Paper No. 33 (July 2005)

24. Tate, D.: Issues involved in implementing a balanced business scorecard in an IT service organization. Total Quality Management \& Business Excellence 11(4), 674-679 (2000)

25. Wallenburg, C.M., Weber, J.: Ursache-Wirkungsbeziehungen der Balanced Scorecard Empirische Erkenntnisse zu ihrer Existenz. WHU Working Paper No. 109 (2006)

26. Wendt, F.: Intraday Margining of Central Counterparties: EU Practice and a Theoretical Evaluation of Benefits and Costs. Netherlands Central Bank, Amsterdam, Netherlands (2006)

27. Wolf, K.: Risikomanagement im Kontext der wertorientierten Unternehmensführung. Deutscher Universitätsverlag, Wiesbaden (2003)

28. Yin, R.K.: Case Study Research: Design and Methods. Sage Publications, Thousand Oaks (2003) 